\title{
Team Whoosh Generator 2013 WSGC Collegiate Rocket Competition
}

\author{
Kirsti Pajunen, Eric Johnson, Chris Larson, Victoria Falcon, James Ihrcke \\ Department of Mechanical Engineering, Milwaukee School of Engineering
}

\begin{abstract}
The objective of the 2013 Wisconsin Space Grant Consortium Collegiate Rocket competition was to design, build, and launch a single-stage high powered rocket that must reach a target altitude of 3000 feet and deploy a parachute(s) electronically for a successful recovery. Upon recovery, the rocket must be determined to be in a flyable condition to be considered a successful launch. Teams receive a launch score based on their combination of reaching the desired altitude and on whether or not the rocket was recovered in a flyable condition.

At the kick-off meeting, Team Whoosh Generator was informed they would be using a Cesaroni I540 motor and a 4.0-in airframe diameter. An RRC2 mini altimeter (from last year's rocket) and an ALTS25 altimeter given to the team at this year's altimeter conference were selected to complete the apogee requirements. Upon reaching apogee (estimated around 3080 feet) a drogue chute deployed under which the rocket descended until it reached an altitude of 500 feet. A second chute then deployed such that a slow decent speed was obtained for landing. A Transolve Beep-X Sonic Locator was activated before launch and was used to aid in recovery of the rocket.
\end{abstract}

Included in this report are design details considered, anticipated performance, photos of the construction process, and flight results.

Team Whoosh Generator thanks the Wisconsin Space Grant Consortium (WSGC) for the funding to make this project possible. 


\subsection{Rocket Design and Construction}

The following subsections will detail the airframe design, nosecone and fin design, rocket stability, electronics bays, pressure relief considerations, and recovery method.

1.1 Airframe design. It was decided to build the rocket from the selection of individual components and not the use of a kit. This seemed most logical because of the many design restrictions (weight, length, diameter, and motor restrictions) and the necessity to reach an altitude between 2500 and 3500 feet. The following sections describe how the airframe of the rocket was designed using these parameters.

Several of the team's members attended the WSGC Altimeter Conference on December 1, 2012. At this conference, the team constructed an electronics bay, built to fit a 4.0-inch outer diameter body tube. Since it was not desired to build an alternate diameter electronics bay, it was decided to design a rocket with a 4.0-inch outer diameter body tube to fit the electronics bay constructed at the altimeter conference. With this parameter set, fewer independent variables remained, making the subsequent rocket design easier.

The body tubes could be selected from several different kinds of materials, including cardboard, fiberglass, and PVC. Cardboard was selected as the body tube material for the rocket because of its simplicity, strength, price, and ease of cutting and drilling. Cardboard has proven to work well from previous years' rockets.

The body tube lengths were heavily dependent on the design restriction of a maximum total rocket length of 72 inches. OpenRocket, a free rocket design software program, was the primary software used to design much of the rocket. OpenRocket was used to calculate optimum body tube lengths. It was found that the lower body tube (to house the motor mount and drogue parachute) would have a length of 25 inches. The upper body tube (to house the main parachute) would have a length of 20 inches. These lengths help to bring the rocket to an apogee of approximately 3000 feet, with favorable centers of gravity and pressure. The total length of the rocket is 55 inches, which is below the 72 inch maximum restriction.

1.2 Nose cone. The nose cone was decided to be a durable plastic 4 inch diameter Madcow Rocketry cone. It is a short ogive cone, 9.5 inches in length. This was chosen because a short, ogive cone has a low coefficient of drag allowing the rocket to achieve a higher apogee. An eyebolt was attached to the bottom of the cone to allow for a stronger point of attachment for the recovery harness.

1.3 Fins. The fins are the main component that determines the location for the center of pressure on a rocket and therefore the stability of the rocket. The design of the fins was determined by placing different shapes and sizes of fins in open rocket until a stable ratio between the center of gravity and center of pressure was obtained. It was determined to use 4 fins spaced evenly around the rocket. 
The fins chosen were A-05 G-10 fiberglass fins from public missiles shown in Figure 1. The fins were attached to the rocket using through the wall construction with epoxy filets on each contact surface shown in Figure 2.

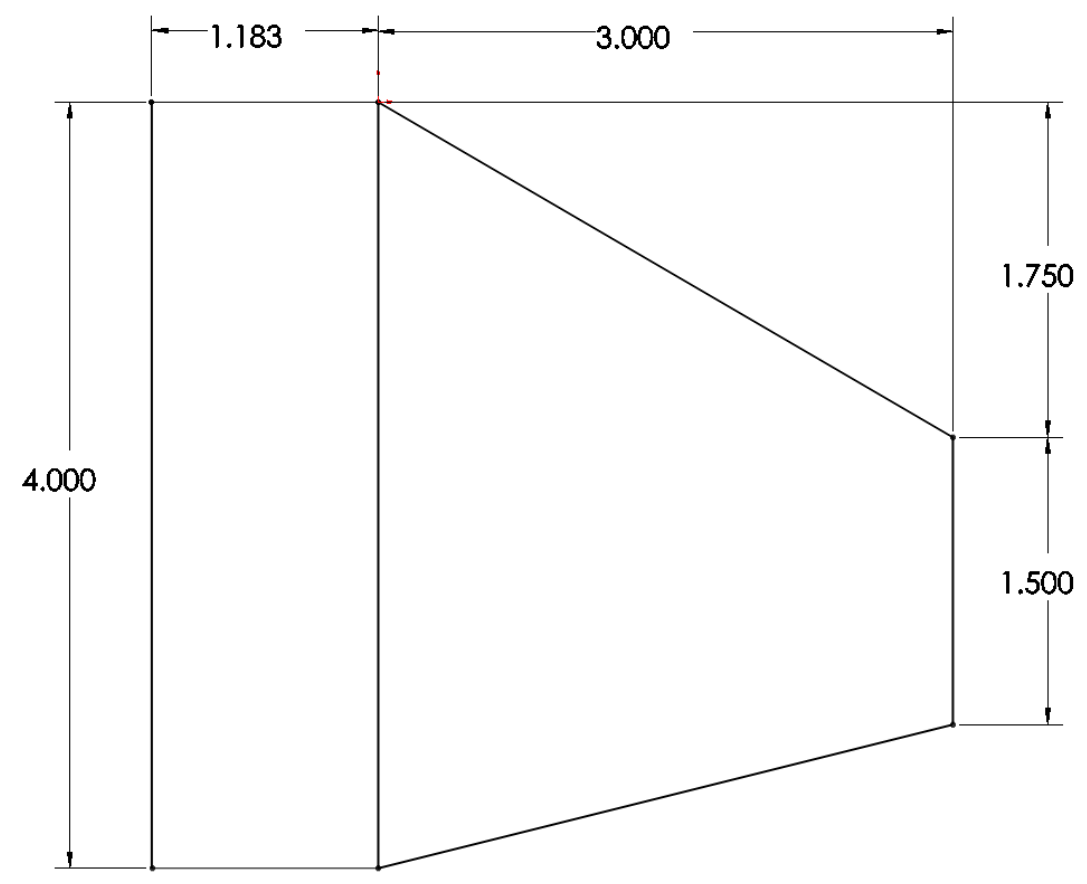

Figure 1: Fin construction with dimensions

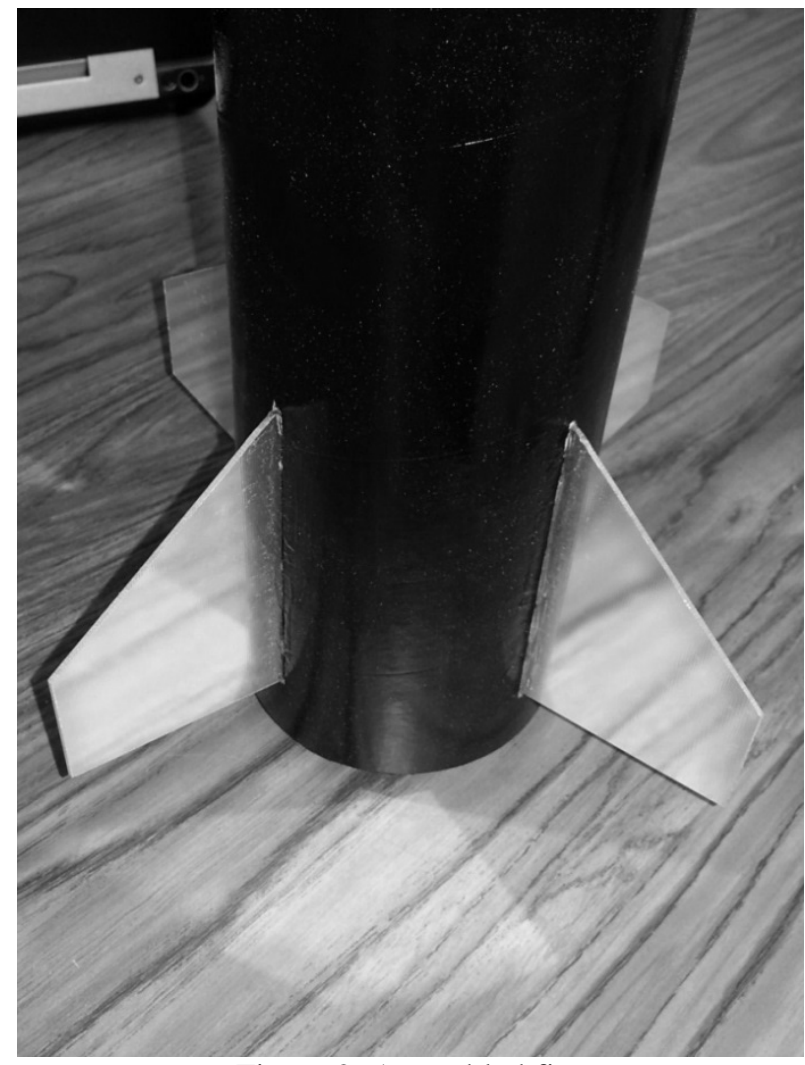

Figure 2: Assembled fins 
1.4 Rocket stability. The relationship between the center of pressure (CP) and center of gravity (CG) is one of the most important relationships in high-powered rocketry. The center of pressure is defined as the point at which aerodynamic forces on the rocket are centered. The center of gravity is the location at which the whole weight of the rocket can be considered to act as a single force. The ratio between the locations relative to the rocket diameter can be used to predict the stability of the rocket during flight. Generally, the center of gravity must be at least one (but not more than two) body tube diameters in front of the center of pressure.

The center of pressure and center of gravity were determined for this design using the OpenRocket software. The results were then compared against the results using Barrowman's Theory, and the two agreed acceptably.

The following assumptions were made during the derivation of Barrowman's theory for predicting the center of pressure (Barrowman, 2013):

1) The flow over the rocket is potential flow.

2) The point of the nose is sharp.

3) Fins are thin flat plates.

4) The angle of attack is near zero.

5) The flow is steady and subsonic.

6) The rocket is a rigid body.

7) The rocket is axially symmetric.

The rocket design presented in this paper did violate some of these assumptions, particularly assumptions 2, 6, and 7. However, the theory was still applied with the understanding that minor uncertainties will be present as a result.

Table 1 shows the locations of the CP and CG and the caliber stability at ignition and at burnout according to the OpenRocket simulation.

\begin{tabular}{|c|c|c|c|}
\hline \multicolumn{4}{|c|}{ Table 1: Locations of CP and CG (In Inches from Nose Cone Tip) } \\
\hline & CP & CG & Stability (Caliber) \\
\hline Ignition & 38.5 & 32.6 & 1.47 \\
\hline Motor Burnout & 38.5 & 31.2 & 1.83 \\
\hline
\end{tabular}

From this analysis, it can be concluded that the rocket will be stable during the entire ascent portion of the flight.

1.5 Electronics bay. The electronics bay was made from a Giant Leap Rocketry avionics bay kit provided to the team at the WSGC Altimeter Conference. It is 8 inches long and has an outer diameter of 3.9 inches allowing it to fit perfectly into a 4 inch diameter airframe. A small piece of airframe, measuring 1.5 inches in length, was cut from a body tube and epoxied in the center of the electronics bay to turn the bay into a coupler. Two barometric altimeters were used in the electronics bay a RRC2 mini used in previous years and an ALTS25 given to the team at the Altimeter Conference. These altimeters will be used to deploy the drogue and main parachutes as 
well as record the altitude of the rocket. The electronics bay also holds the Raven III (WSGC flight data recorder) along with a Transolve BeepX sonic locator which is a location device that puts out a 105 decibel tone allowing location and recovery of the rocket to be easier. A GPS was going to be used but due to space in the electronics bay the sonic locator was chosen. Two key switches were placed 180 degrees apart on the electronics bay to allow easy arming of devices on the launch pad. One key switch is for turning on the WSGC flight data recorder and the other is for arming both altimeters. The sonic locator is activated by a pushbutton on the device. Terminal blocks were placed at either end of the bay to allow easier attachment of black powder charges on launch day. The assembled electronics bay is shown in Figure 3.

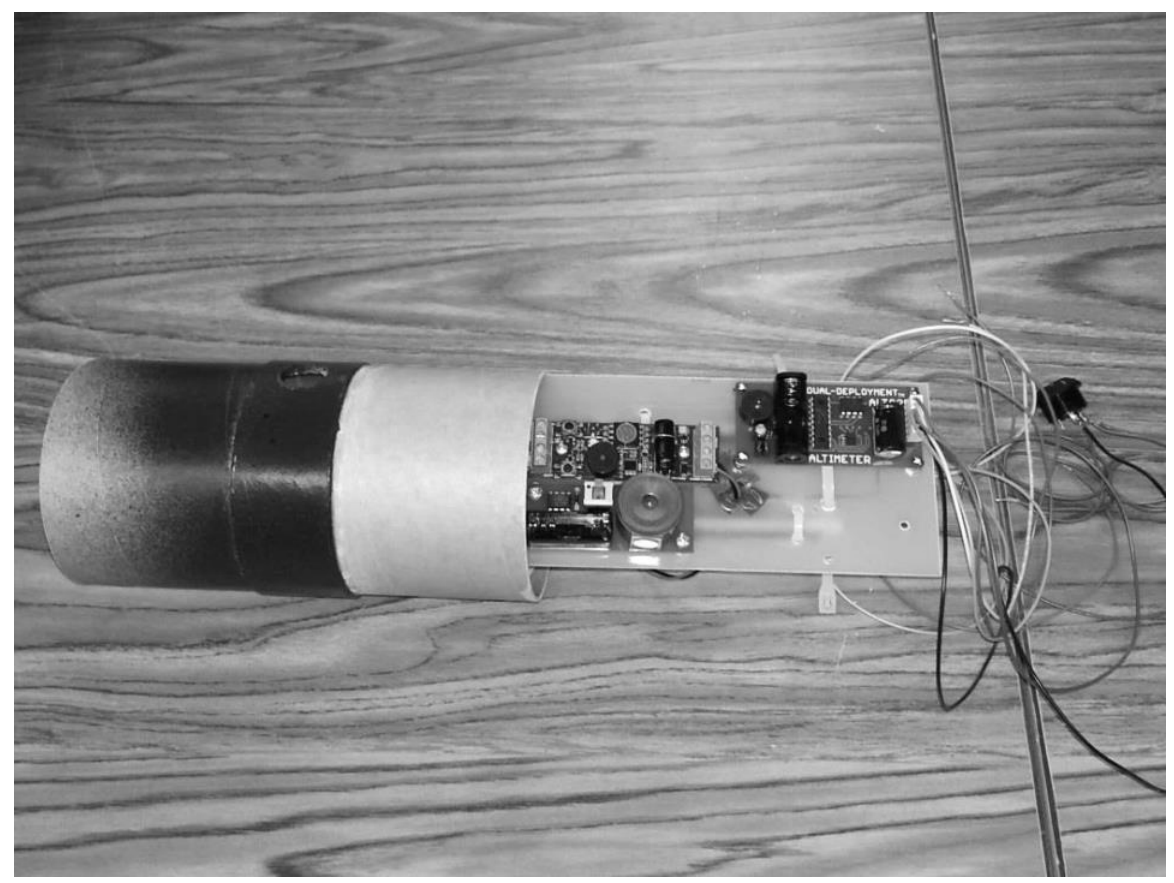

Figure 3: Electronics bay assembly

1.6 Pressure relief. The two barometric altimeters used to deploy the drogue and main parachutes require static pressure port holes. The static port holes are required for pressure equalization between the air inside the bay and the outside air during flight. The parachutes could be deployed too early or too late if the static port holes are not the correct size. The general rule for port hole sizing is to use a $1 / 4$ inch diameter hole (or equivalent area if multiple holes are used) for every 100 cubic inches of volume in the bay. It is also recommended to use at least three holes spaced evenly around the body tube to help negate the effects of crosswinds. The RRC2 mini user manual recommends the use of the following equations for port hole sizing.

The volume of the bay:

$$
\text { Volume }\left(i^{3}\right)=\text { Bay Radius(in) } \times \text { Bay Radius(in) } x \text { Bay Length(in) } \times \pi
$$

The diameter of a single port hole:

$$
\text { Single Port Hole Diameter }=2 \sqrt{\frac{\text { Volume }}{6397.71}}
$$


The area of a single port hole:

$$
\text { Single Vent Area }=\left(\frac{\text { Single Vent Diameter }}{2}\right)^{2} \times \pi
$$

The diameter of multiple port holes:

$$
\text { Multiple Port Hole Diameter }=2 \sqrt{\frac{\text { Single Vent Area }}{(\# \text { of Holes })(\pi)}}
$$

The radius of the electronics bay is 3.9 inches and the length of the bay is 8 inches. This yields a volume of 95.57 cubic inches. The diameter of a single port hole is equal to 0.24 inches with an area of 0.047 square inches. Three holes were used on the electronics bay each with a diameter of 0.141 inches spaced 120 degrees apart.

One quarter inch holes were also drilled into the upper and lower body sections of the rocket. During the rocket's ascent the atmospheric pressure surrounding the rocket decreases. If these holes are not present the higher pressure inside the rocket could cause the rocket to separate and deploy its parachutes early.

1.7 Recovery. The rocket used a dual deployment system. This means the rocket deploys a small drogue parachute at apogee and then a main parachute at a lower altitude to minimize the drift of the rocket allowing easier retrieval of the rocket. A 24 inch drogue chute that deploys at apogee and a 44 inch main SkyAngle Classic parachute that deploys at 600 feet were used. The rocket has a descent rate of 16 feet per second once the main cute has opened. Two altimeters were used for redundancy to ensure the parachutes deploy. The parachutes are shown in Figure 4.

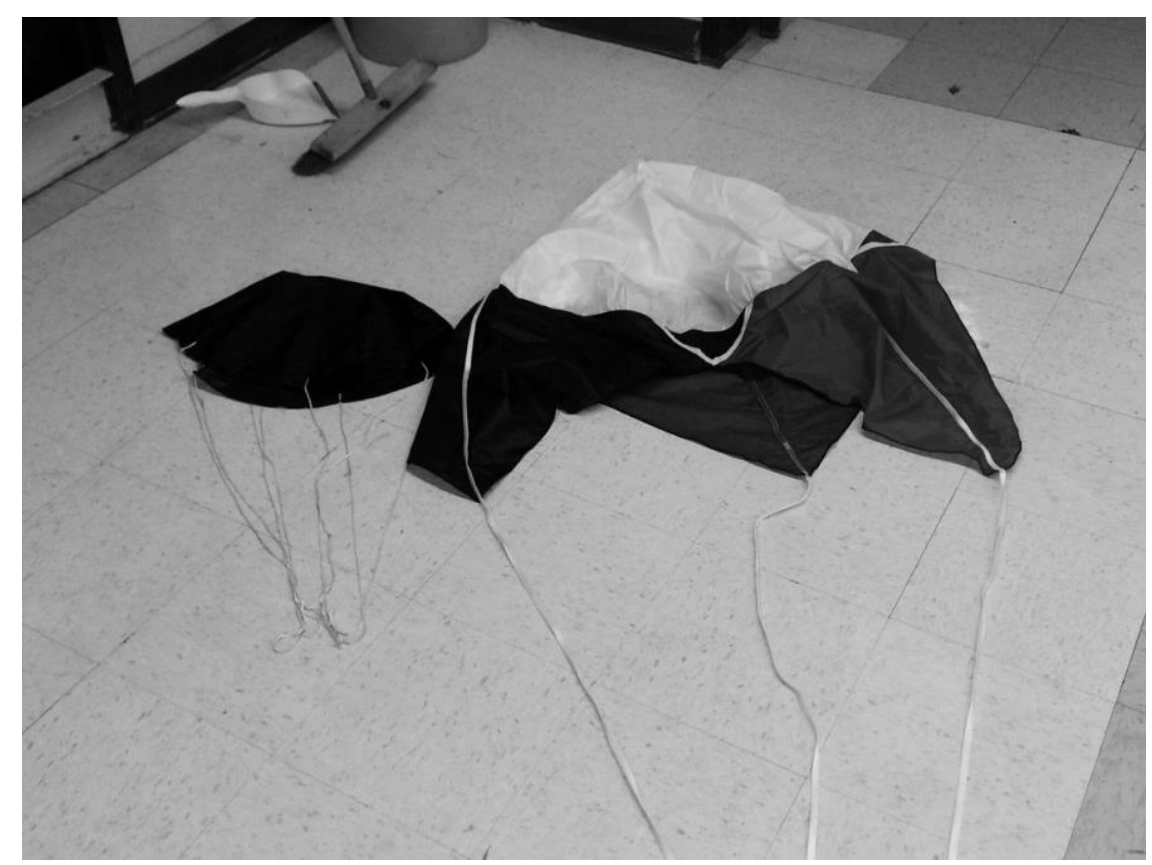

Figure 4: Drogue and main parachutes 


\subsection{Anticipated Performance}

The anticipated performance of the rocket was simulated using two programs: MATLAB and OpenRocket. The results of both simulations were compared to estimate the performance of the rocket on launch day. The following sections detail these simulations.

2.1 MATLAB Simulation. The primary assumptions made were that the rocket would be launched vertically and that the rocket would follow a vertical flight path. Additionally, standard temperature and pressure were assumed to determine air density, which was also assumed to be constant throughout the range of flight.

A MATLAB simulation for the rocket flight performance was then developed using numerical methods. The main function used is from previous years of rocket competitions, but the simulation program itself was developed by the Team Lead this year. The function developed was designed to perform the following:

1) Load thrust data obtained from ThrustCurve.org.

2) Interpolate thrust curve for more discrete steps.

3) Calculate change in mass resulting from burnt propellant.

4) Calculate velocity from the combined impulse from drag, gravity, and thrust.

5) Calculate altitude and acceleration from velocity.

The rocket simulation function operates in the following way.

The velocity of the rocket was determined from the previous momentum plus the impulse. This relationship is shown in Eq. 5:

$$
m_{i} v_{i}+F_{i} \Delta t=m_{i+1} v_{i+1}
$$

Where $F_{i}$ is the net force acting on the rocket and $\Delta t$ is the time step between calculations. The net force acting on the rocket during accent is expressed in Eq. 6:

$$
\begin{aligned}
F_{\text {net }} & =F_{\text {grav }}+F_{\text {drag }}+F_{\text {thrust }} \\
& =m_{i} g+\frac{1}{2} \rho v_{i}^{2} C_{d} A+T_{i}
\end{aligned}
$$

Where:

$\rho$ is the density of air

$C_{d}$ is the coefficient of drag

$A$ is the frontal cross sectional area of the rocket

$T_{i}$ is force from the motor

Substituting Eq. 6 into Eq. 5 and solving for $v_{i+1}$ yields:

$$
v_{i+1}=\frac{1}{m_{i+1}}\left[v_{i} m_{i}+\frac{1}{\Delta t}\left(T_{i}-m_{i} g-k v_{i}^{2}\right)\right]
$$


Where:

$$
k=\frac{1}{2} C_{d} A
$$

Acceleration was calculated using Newton's second law which is expressed in Eq. 8:

$$
a_{i}=\frac{F_{i}}{m_{i}}
$$

The trapezoidal method for approximating the area under a curve was used to calculate the altitude of the rocket during the flight.

The simulation calculated the altitude, velocity, and acceleration versus time for the flight until apogee, based on the assumptions as stated in the Assumptions and Limitations section. The drag coefficient for the MATLAB simulation was found in OpenRocket. The drag coefficient used was 0.43 .

2.2 OpenRocket. OpenRocket is a free, open source, software similar to RockSim. It is capable of calculating acceleration, velocity, and position data while accounting for variables including: elevation, wind speed, and the effects of individual components on performance such as: surface roughness and leading edge fin radii on drag and stability. Also included in the program is the ability to construct full to-scale schematics of the rocket design. From this schematic the CP and CG can also be approximated.

OpenRocket was the main source used in designing the rocket. The rocket was modeled entirely in the program, providing a way to design and calculate proper lengths of body tubes, optimal fin and nosecone designs, rocket weights, acceptable locations of the CP and CG, and drag coefficients. This was an extremely powerful tool, and it has already been mentioned in several previous sections.

2.3 Flight Predictions. The peak altitude, acceleration and velocity for both simulation methods are shown in Error! Reference source not found..

\begin{tabular}{|l|r|r|}
\hline \multicolumn{3}{|c|}{ Table 2: Maximum Flight Predictions } \\
\hline & OpenRocket & MATLAB \\
\hline Altitude (ft) & 3082 & 3011 \\
\hline Velocity (ft/s) & 566 & 562 \\
\hline Acceleration(ft/s ${ }^{\mathbf{2}}$ ) & 574 & 575 \\
\hline
\end{tabular}

\subsection{Results}

Simulations were run to design and estimate flight performance of the rocket. The two programs that were used were OpenRocket and MATLAB code written by the team. Actual flight data was recorded using a Raven 3 flight data recorder provided by WSGC. The flight of the rocket matched well with the estimates of both simulations. A comparison between predicted and measured results is shown in Error! Reference source not found.3. 


\begin{tabular}{|l|c|c|}
\hline \multicolumn{3}{|c|}{ Table 3: Flight Performance Comparisons } \\
\hline & $\begin{array}{c}\text { Apogee } \\
\text { (ft) }\end{array}$ & $\begin{array}{c}\text { Maximum Acceleration } \\
\left.\text { (ft/s } \mathbf{s}^{\mathbf{}}\right)\end{array}$ \\
\hline MATLAB & 3011 & 575 \\
\hline OpenRocket & 3082 & 574 \\
\hline Actual & 3061 & 680 \\
\hline & \multicolumn{2}{|c|}{ Percent Error From Actual (\%) } \\
\hline MATLAB & 2 & 15 \\
\hline OpenRocket & 1 & 15 \\
\hline
\end{tabular}

Predicted and actual altitude and acceleration data are shown in Figure 5 and Figure 6, respectively.

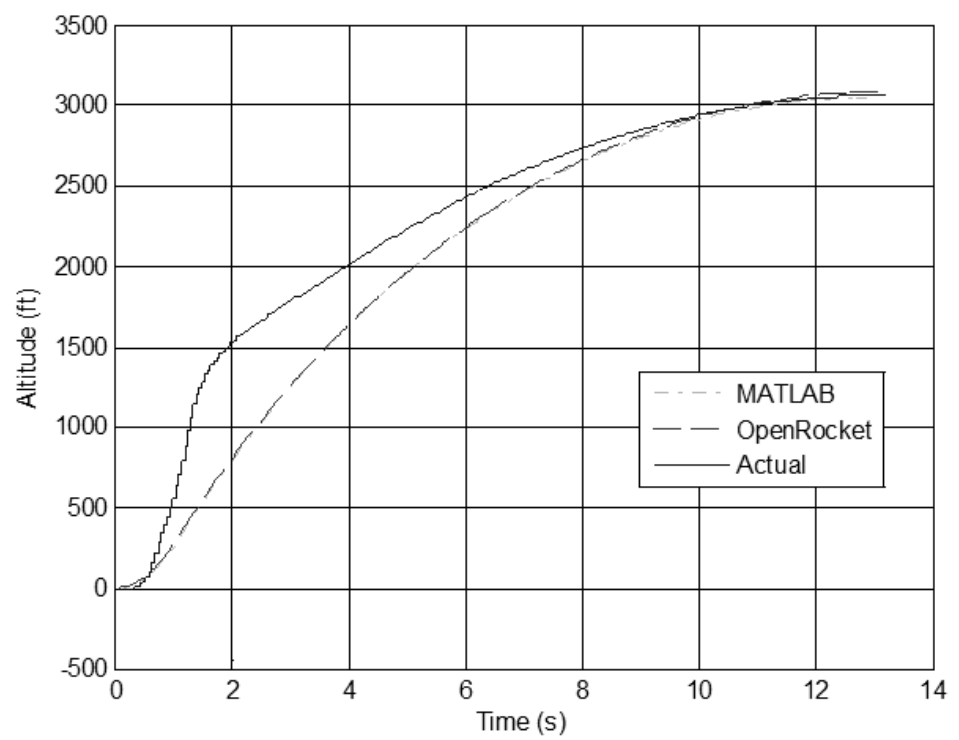

Figure 5: Comparison between predicted and actual

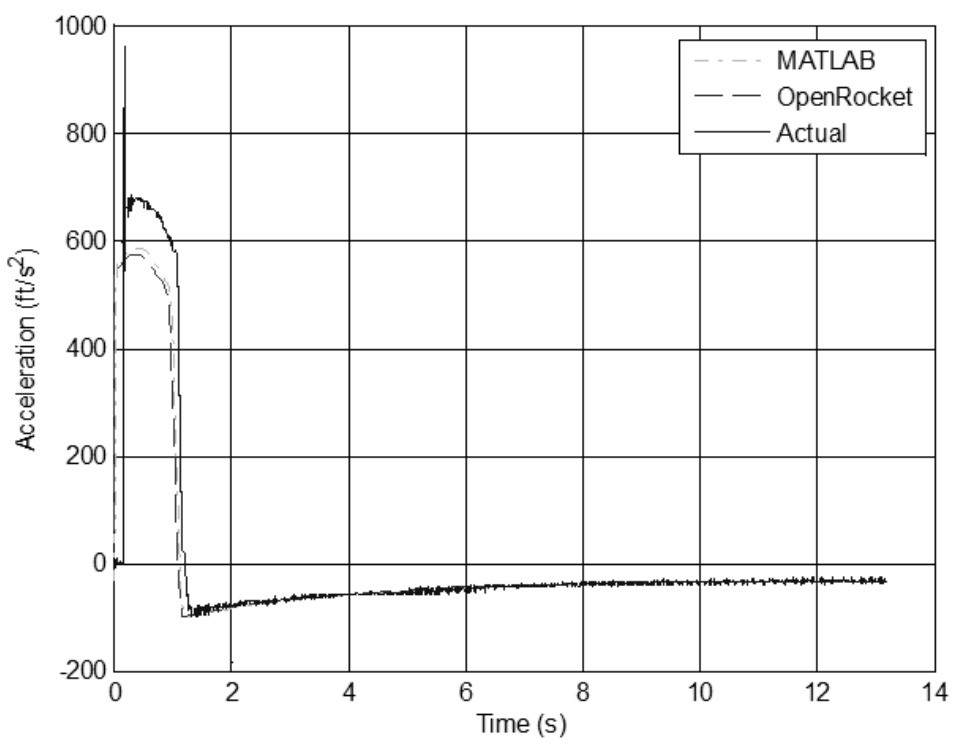

altitude

Figure 6: Comparison between predicted and actual acceleration 
The rocket overshot the desired altitude of 3,000 feet by 61 feet. This was fairly good because MATLAB predicted an apogee of 3,011 feet and OpenRocket predicted 3,082 feet. Since the actual apogee was in between these two predicted values (with percent errors of 1 or $2 \%$ ), the simulations were good representations of the actual flight. For future flights, choosing a weight (reducing it) that places the MATLAB prediction under 3,000 feet and the OpenRocket simulation slightly above 3,000 feet would likely put the actual apogee very close to 3,000 feet.

The maximum acceleration of the rocket was quite higher than predicted. The actual maximum acceleration was $680 \mathrm{ft} / \mathrm{s}^{2}$, with predicted accelerations of around $575 \mathrm{ft} / \mathrm{s}^{2}$. This is a percent error of $15 \%$. While this is not an extremely large percent error, it is significant. This discrepancy in acceleration can be accounted for in many ways. The most significant contributor to this discrepancy is likely the weather conditions on launch day. The air was probably less dense than normal, with a temperature around 46 degrees Fahrenheit. It was also very windy and cloudy, contributing to turbulent flow occurring sooner on the rocket than it normally would. The faster jump to turbulent flow reduced pressure drag on the rocket, allowing for a higher acceleration. The rocket surface also probably was smoother than indicated in OpenRocket, allowing for decreased drag as well. Another significant contributor to the rocket seeing a high acceleration could be the motor performing differently than predicted. The motor could have had more propellant than originally stated in the motor specifications, producing greater thrust and, therefore, greater acceleration.

\subsection{Conclusion}

The rocket was successfully recovered in a flyable condition in compliance with the competition rules. The software utilized for this design predicted the altitude of the rocket to an exceptional margin given the uncertainties present in the launch and design. The acceleration of the rocket was higher than predicted, possibly due to the motor burning differently than expected. Lessons learned through this design will be incorporated into future competitions by returning team members.

\subsection{References}

Barrowman, James. "The Theoretical Prediction of the Center of Pressure." (1966). Apogee Rockets. Web. 13 Apr. 2013.

$<$ http://www.apogeerockets.com/downloads/PDFs/barrowman_report.pdf > . 